\title{
BIOMASSA E ENERGIA
}

\section{José Goldemberg}

Universidade de São Paulo, São Paulo - SP, Brasil

Recebido em 2/12/08; aceito em 20/2/09; publicado na web em 17/3/09

\begin{abstract}
BIOMASS AND ENERGY. Biomass was the dominating source of energy for human activities until the middle 19th century, when coal, oil, gas and other energy sources became increasingly important but it still represents ca. $10 \%$ of the worldwide energy supply. The major part of biomass for energy is still "traditional biomass" used as wood and coal extracted from native forests and thus nonsustainable, used with low efficiency for cooking and home heating, causing pollution problems. This use is largely done in rural areas and it is usually not supported by trading activities. There is now a strong trend to the modernization of biomass use, especially making alcohol from sugar cane thus replacing gasoline, or biodiesel to replace Diesel oil, beyond the production of electricity and vegetable coal using wood from planted forests. As recently as in 2004, sustainable "modern biomass" represented $2 \%$ of worldwide energy consumption. This article discusses the perspectives of the "first" and "second" technology generations for liquid fuel production, as well as biomass gaseification to make electricity or syngas that is in turn used in the Fischer-Tropsch process.
\end{abstract}

Keywords: biomass; energy.

\section{INTRODUÇÃO}

A produção de energia no século 20 foi dominada por combustíveis fósseis (carvão, petróleo e gás) que representavam ainda no início do século 21 , cerca de $80 \%$ de toda a energia produzida no mundo. ${ }^{1}$

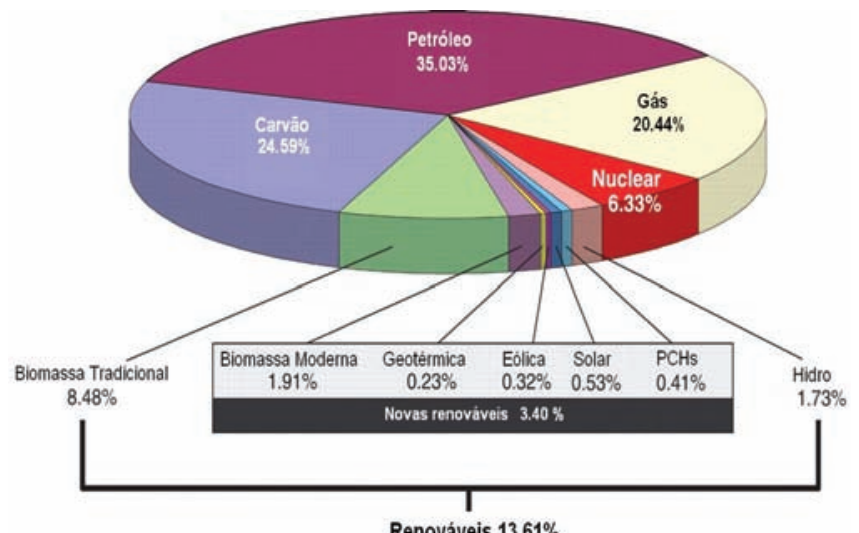

Figura 1. Oferta de energia primária no Brasil em $2004^{2}$

Além dos combustíveis fósseis, energia nuclear e energia hidroelétrica tinham pequenas participações, bem como as novas fontes renováveis de energia (solar, eólica, geotérmica e pequenas centrais hidroelétricas) que são as mais atraentes do ponto de vista ambiental, mas que lamentavelmente representavam apenas $1,5 \%$ da produção mundial. No total todas estas fontes representavam $10 \%$ da produção de energia. Os outros $10 \%$ se originam na biomassa: $8,40 \%$ sob a forma de biomassa tradicional usada de forma primitiva, não sustentável, pelas populações carentes da África, Ásia e parte da América Latina, que derrubam as árvores para aquecer ambientes e cozinhar. Os restantes $1,91 \%$ eram usados como formas modernas de energia, quer gerando eletricidade ou produzindo carvão vegetal

*e-mail: goldemb@iee.usp.br para a indústria siderúrgica quer produzindo etanol, um excelente combustível com octanagem maior do que a gasolina, sem as suas impurezas como particulados e óxidos de enxofre.

A fração da biomassa usada em diferentes regiões do mundo varia muito, desde $2 \%$ nos países da OCDE até $60 \%$ em certas regiões da África (Figura 2).

Em 1850, biomassa representava $85 \%$ do consumo mundial de energia e, mais ainda, antes disso era praticamente a única forma de energia usada pelo homem, além da força dos ventos (para navegação), animais domesticados (na agricultura) e pequenas quantidades de carvão para aquecimento residencial.

Com a Revolução Industrial que se iniciou com o uso das máquinas a vapor no fim do século 18, a importância do carvão, que era pequena, usado principalmente para aquecimento residencial, aumentou para $15 \%$ em 1850 e cresceu rapidamente para $50 \%$ no fim do século $19 .{ }^{3}$ A Figura 3 mostra duas das projeções existentes indicando também a importância crescente da energia solar e o declínio da contribuição das fontes fósseis de energia.

Daí para frente petróleo e gás se tornaram dominantes. Há duas explicações para isso: em primeiro lugar, líquidos como petróleo e gás eram mais fáceis de transportar e deram origem a novas formas de utilização de combustíveis, como motores de combustão interna (ciclos Otto ou Diesel). Além disso, o uso de biomassa na forma primitiva e freqüentemente predatória com que era usada causava desmatamento e degradação do solo é, portanto, desaconselhável. Por essa razão tornou-se conhecido como o combustível dos mais pobres e subdesenvolvidos. O que ocorreu, contudo é que, a partir das últimas décadas do século 20, a "biomassa moderna" começou a representar uma contribuição crescente e está, portanto, em plena recuperação.

As projeções para o futuro indicam que a importância da biomassa aumentará muito, chegando a representar no fim do século 21 de 10 a $20 \%$ de toda a energia usada pela humanidade.

\section{USOS MODERNOS DA BIOMASSA}

Existe um grande número de tecnologias de conversão energética da biomassa, adequadas para aplicações em pequena e grande 


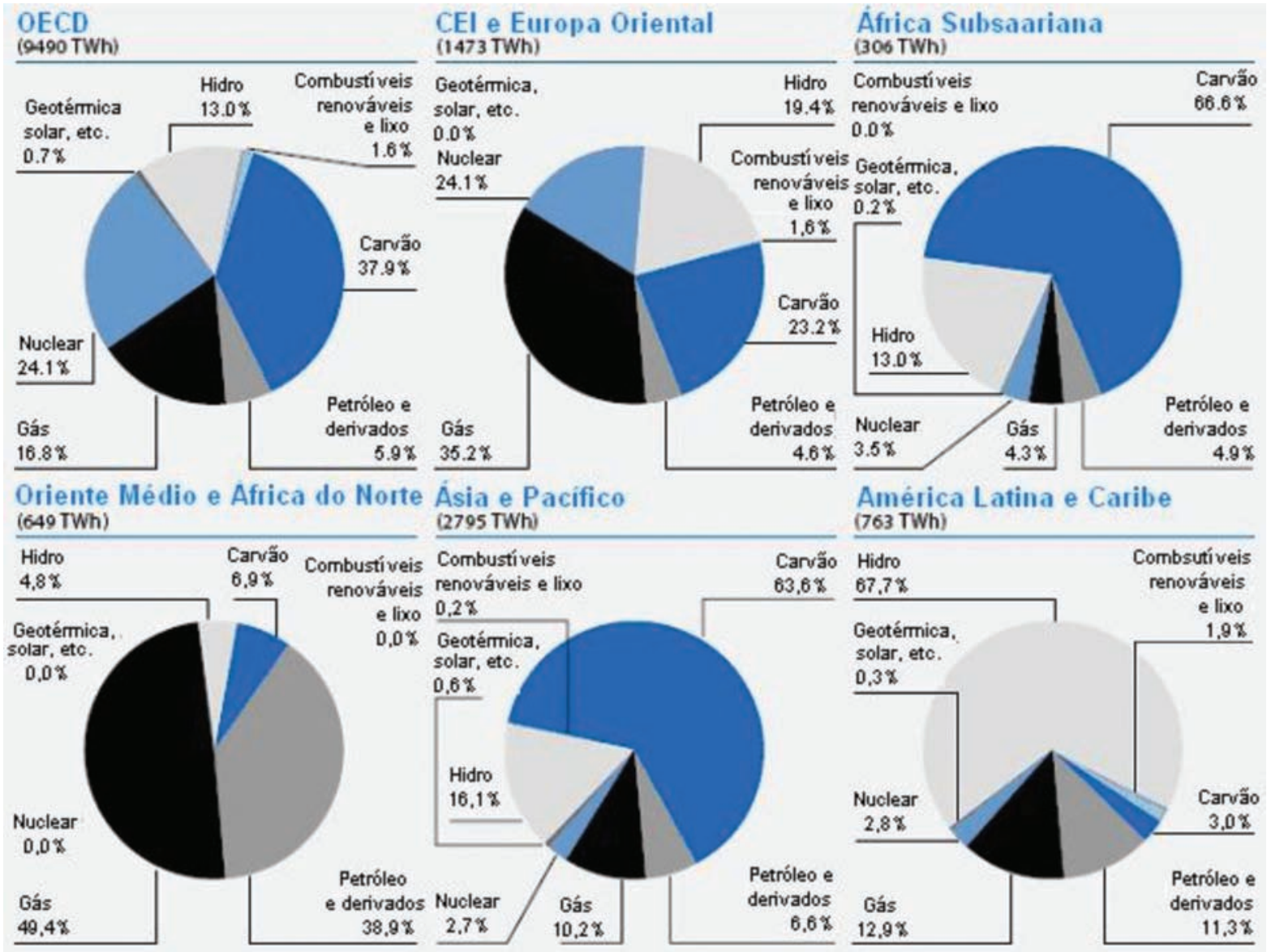

Figura 2. Fração da biomassa usada em diferentes regiões do mundo ${ }^{3}$

\section{Cenário C1}

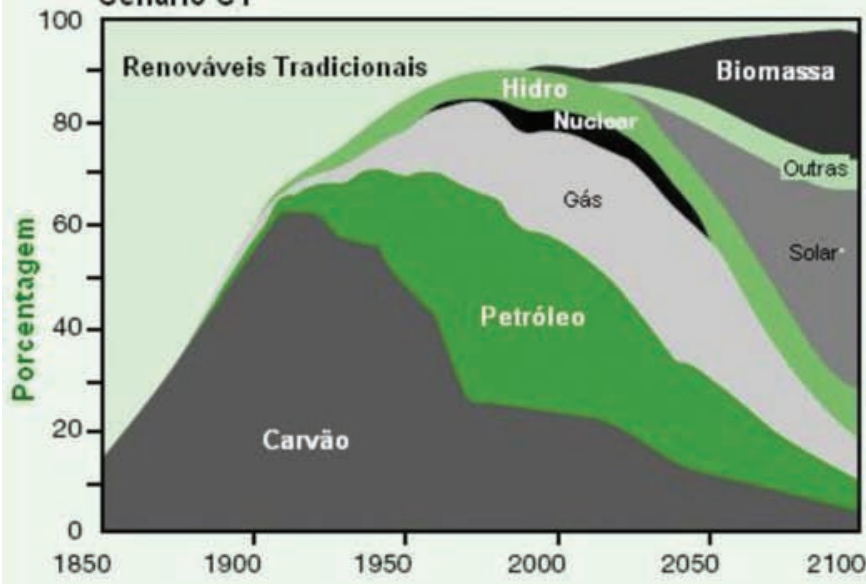

Figura 3. Participação da energia primária, 1850-1990 e cenários para $2100^{3}$

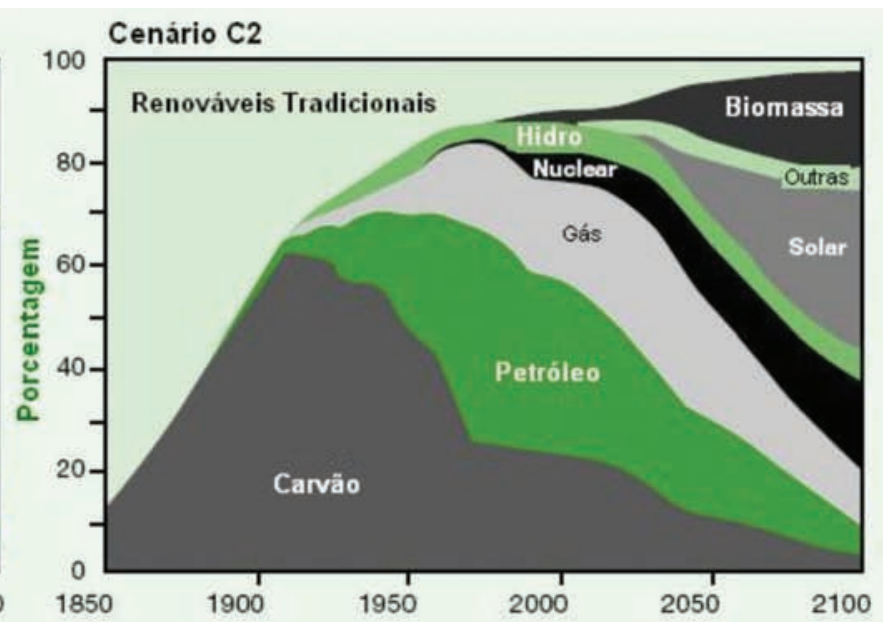

quanto ao futuro da oferta global de petróleo e a de outras opções de combustível disponíveis para o setor de transportes, tais combustíveis representam a melhor das opções de uso da energia de biomassa.

De todas as opções disponíveis, o etanol da cana-de-açúcar é o maior sucesso comercial dos combustíveis de biomassa em produção atualmente. O etanol da cana-de-açúcar possui balanço energético positivo e tem sido beneficiado pelo apoio de políticas governamentais em vários países, inclusive no Brasil, que atualmente abastece aproximadamente $40 \%$ do combustível para veículos de passageiros (um terço da sua demanda total de energia para transporte) com etanol
A Figura 5 esquematiza os diversos caminhos existentes para a produção de biocombustíveis. Dadas as crescentes preocupações escalas. Elas incluem gaseificação, métodos de produção de calor e (cogeração), recuperação de energia de resíduos sólic o setor de transportes (etanol e biodiesel). O recente interesse na energia da biomassa tem dado ênfase em aplicações que produzem combustíveis líquidos para o setor de transportes. (biocombustíveis). A Figura 4 descreve as etapas do processamento do bioetanol de primeira e segunda gerações.
CEI e Europa Oriental

América Latina e Caribe (763 TWh) 

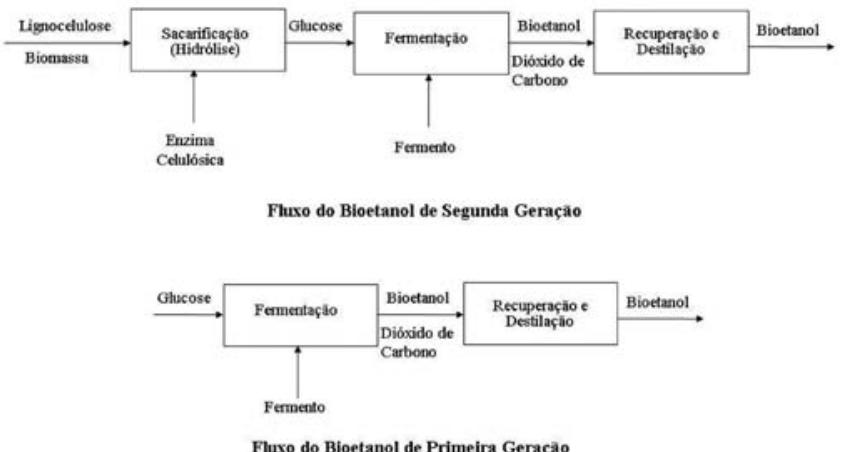

Figura 4. Etapas do processamento do bioetanol de primeira e segunda geração

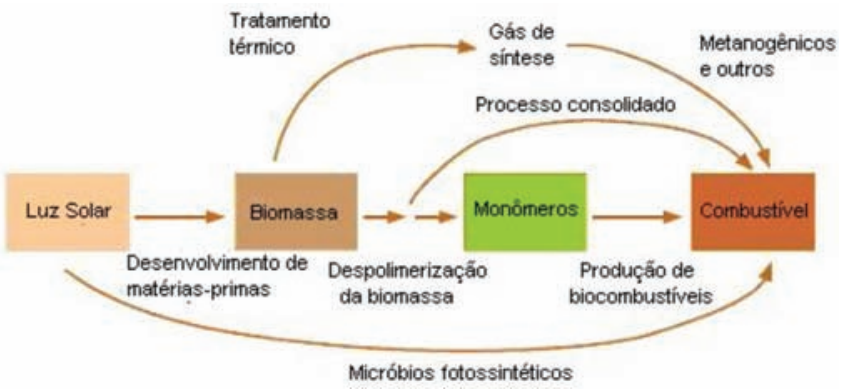

Figura 5. Vias potenciais para a produção de biocombustíveis ${ }^{5}$ Nota: A atual produção de biocombustiveis através de matéria-prima de biomassa de lignocelulose - incluindo a biomassa cultivada para produção de energia e resíduos orgânicos (e.g., palha de arroz e trigo, resíduos de madeira) - procede através de um processo de pré-tratamento que separa a lignina da longa cadeia de açúcares (celulose e hemicelulose), com a despolimerização em açúcar simples, e, finalmente, fermentação em álcool. Caminhos alternativos que estão sendo explorados incluem a possível combinação do pré-tratamento, despolimerização e fermentação num só processo. Um caminho alternativo envolve a conversão da biomassa em gás sintético (mistura de monóxido de carbono e hidrogênio), o qual é, então, convertido em combustível hidrocarboneto. A produção industrial de biocombustíveis via micróbios, como a alga ou bactéria, é outra possibilidade

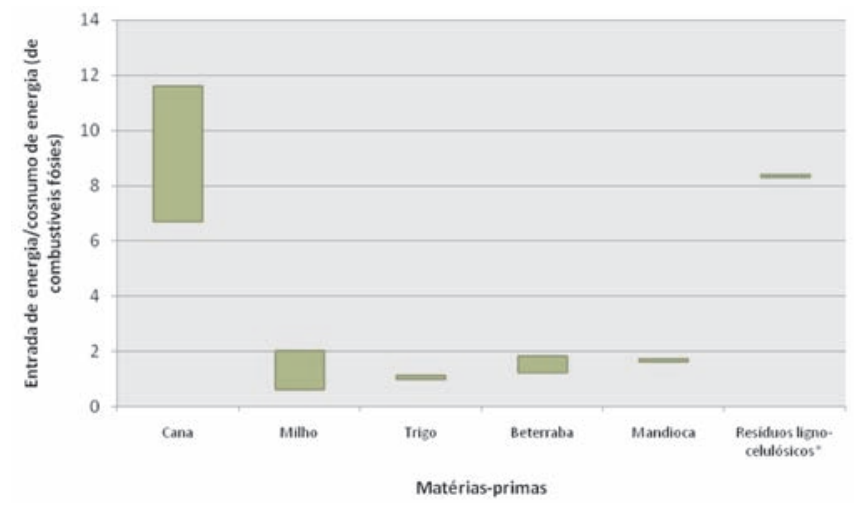

Figura 6. Balanço energético do etanol produzido a partir de diferentes matérias-primas ${ }^{7-9}$

Nota: *baseado em dados teóricos, tecnologia em desenvolvimento

da cana-de-açúcar. ${ }^{2,6} \mathrm{O}$ balanço energético para a produção de etanol a partir de vários produtos agrícolas é dado na Figura 6.

Globalmente, existem oportunidades para expandir a produção de etanol da cana-de-açúcar: quase 100 países produzem cana-de- açúcar e as tecnologias de conversão são disponíveis. Além disso, a experiência brasileira sugere que os impactos ambientais adversos associados com a produção em larga-escala de etanol da cana-deaçúcar podem ser significantemente mitigados. ${ }^{10} \mathrm{O}$ etanol também está sendo produzido em escala comercial a partir do milho nos Estados Unidos, o qual subsidiou sua produção por muitos anos e mais recentemente adotou outro tipo de combustível de transporte baseado na biomassa - o biodiesel - que tornou-se comercialmente disponível recentemente, como um resultado de programas na Europa e América do Norte. No entanto, essa opção oferece limitado potencial de redução de custos de produção e sua viabilidade é passível de continuar dependendo de incentivos externos, como subsídios agrícolas. Além disso, adesão às especificações do combustível e efetivo controle de qualidade são fatores importantes para garantir a viabilidade comercial do biodiesel. Avanços tecnológicos recentes têm envolvido esforços para diversificar a cadeia de fornecimento de biodiesel através, por exemplo, do uso do bioetanol ao invés do metanol do carvão mineral como matéria-prima.

A energia do biogás da degradação anaeróbica em aterros sanitários, estações de tratamento de esgoto, e terrenos de tratamento de estrume é considerada uma opção de baixo custo, uma vez que pode se beneficiar de créditos de carbono disponíveis através do Mecanismo de Desenvolvimento Limpo (MDL). Essa forma de energia de biomassa não só substitui a combustão de combustíveis fósseis, mas reduz as emissões de metano, um gás de efeito-estufa mais potente do que o dióxido de carbono.

Tecnologias de conversão de biomassa para formas utilizáveis comercialmente variam em termos de escala, qualidade do combustível e custo. Tecnologias de larga-escala que já estão no mercado incluem combustão em leito fixo, leitos fluidizados, combustão e co-combustão de carvão e biomassa, recuperação de resíduos sólidos urbanos assim como diversos tipos de sistemas para gaseificação, pirólise, etc. Muitas dessas tecnologias não estão disponíveis comercialmente ainda em países em desenvolvimento.

\section{O FUTURO DA BIOMASSA MODERNA}

Assim como outras opções de energia renovável, o potencial teórico para a energia da biomassa é enorme. Dos aproximadamente 100.000 Terawatts de fluxo de energia solar que atingem a superfície da Terra, cerca de 4.000 Terawatts atingem os 1,5 bilhões de hectares de plantações existentes no mundo. Admitindo que as tecnologias de biomassa moderna possam atingir uma eficiência da conversão energética de $1 \%$, essas plantações poderiam, em teoria, produzir 40 Terawatts de fluxo de energia, ou mais de 3 vezes o atual fluxo de abastecimento global de energia primária de 14 Terawatts. Essa comparação não tem a intenção de sugerir que todas as terras cultiváveis deveriam ser usadas para a produção de energia, mas somente para ilustrar que há espaço para uma expansão significativa da contribuição energética da biomassa moderna, dado que essa contribuição foi estimada em somente 0,17 Gigawatts em 2003. ${ }^{11,12}$

Há numerosas áreas em países em desenvolvimento onde o uso de matéria-prima de biocombustíveis melhorados, pode ser substituído pela atual utilização de plantas nativas. O uso eficaz dessas novas matérias-primas de biomassa para a co-produção local de aquecimento, eletricidade e combustível de transporte também teria um impacto profundo na capacidade das populações rurais de acessar formas de energia modernas e mais limpas. Soluções energéticas que podem ser desenvolvidas com investimento modesto de capital serão um elemento crucial de uma efetiva estratégia energética. Também será crucial - como parte de qualquer expansão em largaescala da produção da energia de biomassa - gerenciar as demandas competitivas de produção de alimentos e preservação ambiental. Nas 
áreas onde a base dos recursos for suficiente para sustentar ambos, alimentos e produção de energia, ou em casos onde é possível fazer uso complementar das mesmas matérias-primas (ex., usando resíduos de produção de alimentos para produção de energia), as restrições ao uso de terra podem não ser um problema grave.

Em outras áreas, entretanto, o potencial para produção de energia para deslocar a produção de alimentos pode gerar preocupações especialmente se a produção de alimentos serve a população local, enquanto a produção de energia é prioritariamente para exportação. Este pode ser o caso em vários países em desenvolvimento, em particular no estado de São Paulo, onde a expansão das plantações de cana-de-açúcar para produção de etanol poderia reduzir a produção de alimentos. Na prática isto não ocorre porque a expansão no estado tem ocorrido em pastagens degradadas. ${ }^{13}$ Exemplo desta situação ocorreu quando um forte aumento nos preços de milho devido, em parte, à expansão rápida de demanda por etanol de milho nos Estados Unidos, provocou protestos e distúrbios no México, no início de 2007.

Algumas das mais promissoras oportunidades para solucionar estes conflitos e expandir a contribuição energética da biomassa moderna envolvem avanços de vanguarda nas ciências biológicas e químicas, inclusive o desenvolvimento de plantios designados para produção de energia e a simulação artificial de processos biológicos naturais, tais como a fotossíntese. Descobertas nas novas fronteiras da pesquisa de energia da biomassa, em qualquer das muitas áreas de pesquisa descritas no Quadro 1, poderiam ter profundas implicações para o futuro do uso da energia de biomassa. Como outras opções para o uso de recursos renováveis, a magnitude da contribuição da biomassa dependerá de quanto progresso poderá ser alcançado em áreas-chave como: redução de custos; mitigação de impactos ambientais, uso da água, produtos químicos (pesticidas ou fertilizantes), perdas na biodiversidade; e minimização da pressão em recursos escassos do solo em termos de requisitos competitivos para produção de alimentos e fibras e preservação do habitat.

Soluções que simultaneamente se proponham a remover todos esses obstáculos envolvem expandir a disponibilidade de solo para a produção de energia; integrar o desenvolvimento da energia de biomassa com as práticas agrícolas e florestais sustentáveis; melhorar a produtividade de plantios com consideração ao solo, à água e ao uso de nutrientes; e desenvolver tecnologias de produção avançada e conversão. Biocombustíveis produzidos da lignocelulose, em preferência ao amido, aparentam ser mais promissoras, tanto em termos de minimizar potenciais conflitos entre produção alimentícia e energética e em termos de maximizar os benefícios ambientais (inclusive a redução de gases do efeito estufa) relativos ao uso de combustíveis fósseis.

Significativos avanços têm sido alcançados mundialmente com relação à produtividade agrícola. Entre 1950 e 1999, as áreas usadas para plantio de cereal aumentaram 17\%. Durante esse tempo, a produtividade da safra de cereais subiu $183 \% .{ }^{14} \mathrm{~A}$ introdução de novas variedades de espécies diversificou as culturas de plantio, permitindo uma colheita eficaz em diferentes tipos de solos, climas e condições de água e também melhores safras.

Para dar um exemplo, a União Européia e os Estados Unidos estão realizando grandes esforços em Pesquisa e Desenvolvimento (P\&D) para melhorar a competitividade dos custos da produção comercial do etanol. Os esforços atuais estão focados em promover a recuperação eficaz de açúcares através da hidrólise de frações de celulose e hemicelulose da biomassa, assim como uma melhor fermentação do açúcar. ${ }^{12}$

Com o crescente aumento dos preços de óleo e gás natural, e com os novos incentivos gerados pela emergência do mercado de carbono, o gás de aterros sanitários, bagaço da cana-de-açúcar, biodiesel, madeira de reflorestamento, e esquemas resíduo-energia estão também se tornando opções atrativas. Baseado nas atuais tendências no desenvolvimento tecnológico, espera-se que os custos de recuperação da energia de biomassa se reduzam em até dois terços em 20 anos. $^{12}$

O progresso no desenvolvimento de alternativas para a energia de biomassa, além de aliviar a pressão em recursos finitos de combustíveis fósseis, pode reduzir os custos de mitigação de emissões de carbono. O etanol de cana-de-açúcar, por exemplo, tem um balanço energético positivo de oito para um, e um custo aproximadamente nulo de mitigação de carbono. Como uma tecnologia que evita emissões de gases de efeito-estufa, o bioetanol poderia, em breve, alcançar custos negativos conforme se torna mais barato do que a gasolina - mesmo sem subsídios governamentais - em alguns mercados.

Por outro lado, muito do etanol e do biodiesel produzidos comercialmente nos países OCDE têm, atualmente, custos de mitigação de carbono na faixa de US\$60-400 por tonelada de dióxido de carbono no ciclo de vida que englobe todo o processo. ${ }^{5} \mathrm{O}$ uso de fertilizantes no cultivo da biomassa, por exemplo, pode produzir emissões de óxido nitroso, um gás de efeito-estufa extremamente potente - o que reduziria os benefícios climáticos decorrentes do uso do petróleo. Da mesma forma, a conversão da biomassa em combustível líquido requer energia e - dependendo da eficiência do processo de conversão e das fontes energéticas usadas - pode também produzir significantes emissões reduzindo os benefícios que adviriam do seu uso. Melhorar o desempenho dos combustíveis de biomassa no que se refere à mitigação das mudanças climáticas depende, então, da redução desses aportes de energia.

O interesse está também crescendo no desenvolvimento de sistemas integrados que permitiriam a co-produção de matéria-prima energética com outro produto agrícola, como meio de atingir economias significativas no custo e benefícios ambientais. Por exemplo, a produção de biodiesel pode fazer sentido somente se utilizadas sementes não comestíveis (por ambos, humanos e animais) como matéria-prima ou se puder ser feita com o cultivo de alimento animal.

Outros exemplos potencialmente promissores de sistemas integrados envolvem processos de gaseificação que poderiam permitir a co-produção de múltiplos produtos, inclusive de eletricidade, combustíveis líquidos de transporte e produtos químicos. Tecnologias de gaseificação podem ser usadas com diversas matérias-primas, incluindo carvão mineral e uma ampla gama de materiais orgânicos. Em geral, o processo envolve a produção de gás sintético (composto primeiramente de monóxido de carbono e hidrogênio) de qualquer carbono - e hidrogênio; o gás sintético pode então ser usado para dirigir turbinas de alta eficiência e como matéria-prima para manufatura de uma variedade de produtos químicos sintéticos ou combustíveis.

A tecnologia de gaseificação em pequena escala pode eventualmente emergir como uma opção promissora para melhorar o acesso à energia em áreas isoladas. Por enquanto, o mais importante uso de recursos de biomassa disponíveis localmente pode estar no seu uso conjunto com modernas tecnologias de combustão como substituto ao óleo diesel, o qual é, agora, comumente usado em motores a diesel antigos e ineficazes.

A indústria da biotecnologia atualmente está começando a investigar processos de produção mais avançados do que as opções atuais, como hidrólise do etanol e fermentação, enzimas de biodiesel, maior fixação de carbono nas raízes, e recuperação melhorada de óleo. ${ }^{8}$ Avanços na engenharia genética já permitem o desenvolvimento de estirpes de resistência a doenças para as safras que são viáveis no ambiente (como solos degradados) que eram antes considerados inadequados para cultivos, assim como para safras que exigem menos insumos químicos e água. Novas tecnologias de alto nível em desenvolvimento incluem técnicas de bioprocessamento de lignocelulose que permitiriam a co-produção de combustíveis e produtos químicos 


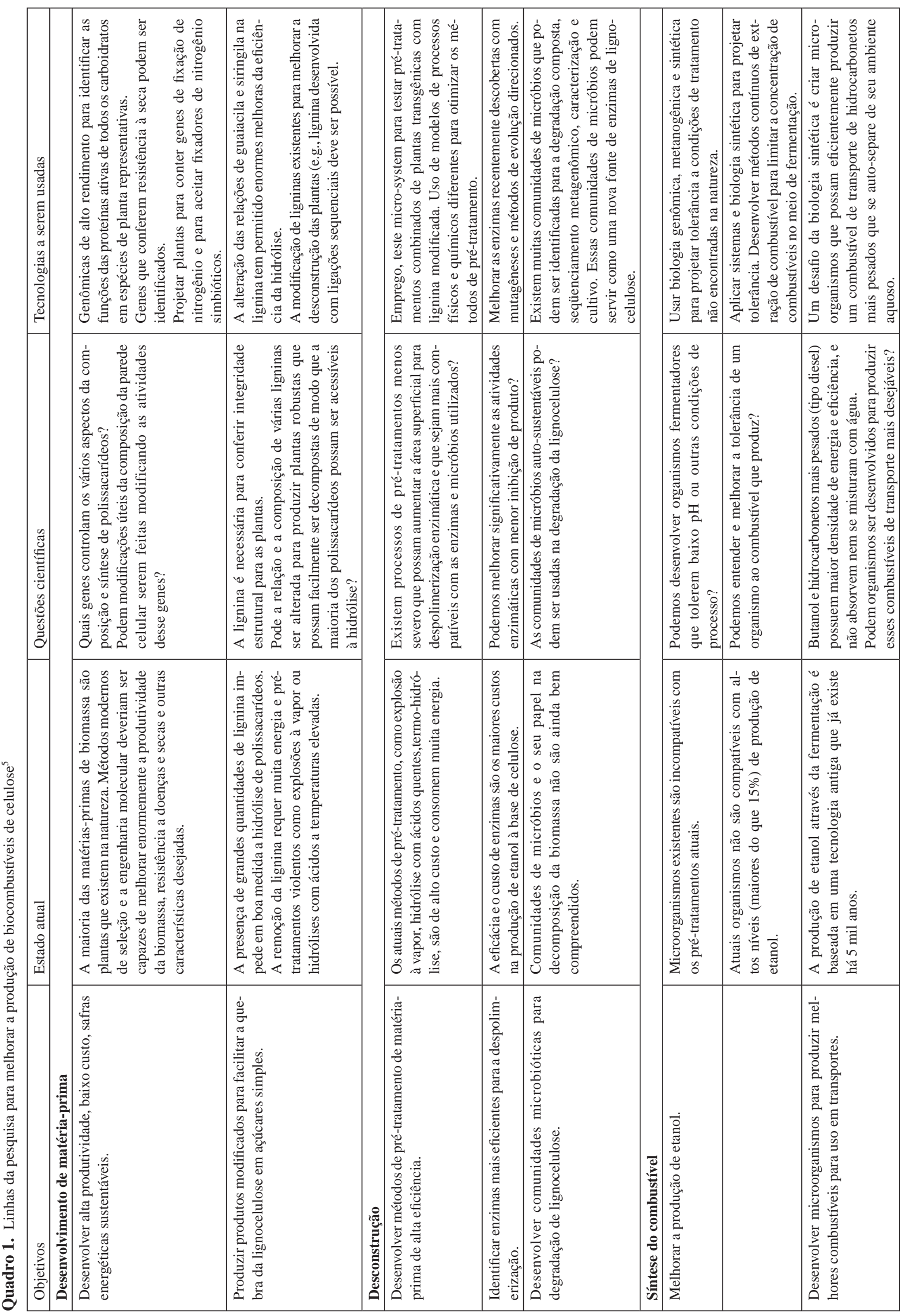


nas biorefinarias, incluindo modificações genéticas para a obtenção de matérias-primas de biomassa além de facilitar a aplicação de tecnologias de processo que poderiam alcançar $70-90$ por cento de eficiência na conversão energética.

\section{FRONTEIRAS NA PRODUÇÃO DE BIOCOMBUSTÍVEIS}

Atualmente, a indústria de biocombustíveis é baseada essencialmente na produção de etanol através da fermentação de açúcares ou amidos e na produção de biodiesel derivado de óleos vegetais. O uso de materiais de biomassa de lignocelulose (de madeira ou fibroso) em contraste aos açúcares e amidos - tem, entretanto, maior potencial para maximização da eficiência de conversão de luz solar, água e nutrientes em biocombustíveis.

Plantas perenes, como as gramíneas ou árvores de rápido crescimento são particularmente atrativas para a produção em larga-escala de biocombustíveis sustentáveis, por diversas razões: não requerem lavra por aproximadamente 10-15 anos após o primeiro plantio; raízes de longa vida podem ser desenvolvidas para estabelecer interações simbióticas com bactérias para fixar nitrogênio e nutrientes minerais, resultando em uma menor perda de nitratos e erosão do solo. Algumas espécies perenes retiram uma fração substancial de nutrientes minerais de porções de plantas da superfície. Gramíneas selvagens como miscanthus têm produzido até 65 toneladas secas por hectare (suficiente para produzir 24.600 litros de etanol por hectare) em solos não irrigados e não fertilizados, nos Estados Unidos. Isso é aproximadamente cinco vezes maior do que a produtividade comum do açúcar de beterraba ou matéria-prima de amido, como o milho. Em geral, o rendimento de biodiesel da maioria das matérias-primas - exceto óleo de dendê - é menor. Os atuais métodos de produção de etanol de matéria-prima celulósica procedem em três etapas: pré-tratamento termoquímico da biomassa não-preparada para fazer polímeros de celulose e hemicelulose complexos mais acessíveis ao ataque enzimático; aplicação de coquetéis enzimáticos especiais que hidrolisam a parede celular polissacarídea em uma mistura de açúcares simples; e fermentação, mediante bactéria ou levedura, para converter esses açúcares em etanol.

A fração rica em lignina, que é separada da celulose e da hemicelulose pode ser queimada para fornecer energia às biorefinarias ou convertida em gás de síntese e após em combustíveis pelo processo de Fischer-Tropsch. Os métodos atuais dependem de etapas complexas e intensivas no uso de energia, onde o pré-tratamento é incompatível com a decomposição enzimática. Como resultado, fases de neutralização adicional são necessárias, adicionando ao custo total e reduzindo a eficácia do processo. Nas futuras biorefinarias, os processos de despolimerização e de fermentação podem ser consolidados em uma só etapa usando uma mistura de organismos na conversão da biomassa em etanol. Melhorias significantes na redução do uso de energia, custos de enzimas e no número de etapas do processo são também possíveis.

A aplicação de avanços de áreas de desenvolvimento rápido de ciência e tecnologia, como a biologia sintética e o alto rendimento de funcionalidades genômicas, permite prever rápidas melhoras na matéria-prima e na conversão da mesma em biocombustíveis. Possíveis áreas de pesquisa que incrementariam a produção de biomassa e sua conversão em combustível são listadas no Quadro 1. Materiais celulósicos como arroz e palha de trigo, sabugo de milho e outras safras e resíduos florestais podem servir de fontes de matéria-prima celulósica.

O desenvolvimento de micróbios fotossintéticos que produzem lipídios ou hidrocarbonetos também possui ótimo potencial para produção de biocombustíveis. Apesar de ser pouco provável que a produção agrícola de biomassa utilizável exceda a eficiência de conversão solar de 1-2\%, algas podem converter energia solar a eficiências que excedem $10 \%$.

A combinação de processos microbiais anaeróbios e aeróbios pode ser separadamente otimizada, para que o precursor de um combustível possa ser produzido em um ambiente anaeróbico e o produto final em um ambiente aeróbico. O cultivo de algas teria a vantagem de alta eficiência mas a produção desses microorganismos poderá requerer uma infra-estrutura de alto custo de capital.

\section{REFERÊNCIAS}

1. World Energy Assessment - WEA 2000; Energy and the challenge of sustainability. United Nations Development Programme, United Nations Development of Economic and Social Affairs and World Energy Council.

2. Goldemberg, J.; Science 2007, 315, 808.

3. World Energy Assessment - WEA. 2004; Energy and the challenge of sustainability. United Nations Development Programme: Overview 2004 update.

4. Larson, D. E.; Biofuel production technologies: status and prospect. In: United Nations Conference on Trade and Development. http:// r0.unctad.org/ghg/events/biofuels/ LarsonAHEM19\%20June\%202007. pdf, acessada em Novembro 2007.

5. InterAcademy Council - IAC; Biomass. Lighting the Way: Toward a Sustainable Energy Future, 2007, p. 111.

6. Goldemberg, J.; Biotechnol Biofuels 2008, 1, 1.

7. Macedo, I. C.; Seabra, J. E. A.; Silva, J. E. A. R.; Greenhouse gases emissions in the production and use of ethanol from sugarcane in Brazil: The 2005/2006 averages and a prediction for 2020, Biomass and Bioenergy 2008, ??, ???.

8. UK DTI, 2003; Technology status review and carbon abatement potential of renewable transport fuels in the UK. Report B/U2/00785/REP, 2003. Available at: http://www.berr.gov.uk/files/file15003.pdf, acessada em Novembro 2008.

9. USDA, 1995; Estimating the Net Energy Balance of Corn Ethanol. Report by Shapouri, H., Duffield, J.A., Graboski, M.S. U.S. Department of Agriculture, Economic Research Service, Office of Energy. Agricultural Economic Report No. 721. July, 1995. Available at: http://www.ers.usda. gov/publications/aer721/AER721.PDF, acessada em Novembro 2008.

10. Goldemberg, J.; Coelho, S. T.; Energy Policy 2004, 32, 711.

11. Somerville, C.; Energy from Biomass. Workshop presentation for the InterAcademy Council study report, Lighting the Way: Toward a Sustainable Energy Future, 2005, IAC, Amsterdam.

12. Macedo, I. C.; 2005. Biomass as a Source of Energy. Unpublished paper commissioned for the InterAcademy Council study report, Lighting the Way: Toward a Sustainable Energy Future, 2005, IAC, Amsterdam.

13. Goldemberg, J.; Guardabassi, P.; Energy Policy 2008, doi:10.1016/ j.enpol.2008.08.031.

14. FAOSTAT, "FAO Statistical Database", 2008. 